\title{
Evaluation of sub-zonal air flow models for the prediction of local interior boundary conditions - natural and forced convection cases
}

\author{
Corresponding author: \\ Paul W.M.H. Steskens, PhD, \\ Laboratory of Energy Characteristics, Belgian Building Research Institute, Av. P. Holoffe 21, B-1342 Limelette, \\ Belgium; \\ E-mail: paul.steskens@bbri.be \\ Co-authors: \\ Hans Janssen, Assoc. Professor, \\ Building Physics Section, Department of Civil Engineering, K.U. Leuven, Kasteelpark Arenberg 40, B-3001 \\ Heverlee Belgium; \\ Carsten Rode, Professor, \\ Department of Civil Engineering, Technical University of Denmark, Building 118, DK-2800 Kgs. Lyngby, Denmark;
}

\section{Short Title:}

Sub-zonal airflow model for local boundary conditions

KEYWORDS: Boundary conditions, sub-zonal airflow model.

\begin{abstract}
:
Currently, researchers are striving to advance the possibilities to calculate the integrated phenomena of heat, air and moisture flows in buildings, with specific focus on the interactions between the building zones and building components. This paper presents an investigation of the capability and applicability of the sub-zonal airflow model to predict the local indoor environmental conditions as well as the local surface transfer coefficients near building components. Two test cases were analyzed for respectively natural and forced convection in a room. The simulation results predicted from the sub-zonal airflow models are compared to experimental data and numerical CFD (Computational Fluid Dynamics) results. The study shows that subzonal models combined with an appropriate surface transfer coefficient model are able to give reliable predictions of the local indoor environmental conditions and surface transfer coefficients near the building component for the analyzed cases. The relatively short computation time and flexibility of the sub-zonal model makes the application attractive for transient simulation of heat, air and moisture transport in buildings. However, the availability of appropriate reference conditions, for example experimental or numerical results, is a prerequisite for the development of a reliable sub-zonal model.
\end{abstract}


Postprint: Steskens PWMH, Janssen H, Rode C, 2013. Evaluation of sub-zonal air flow models for the prediction of local interior boundary conditions - natural and forced convection cases, Indoor and Built Environ-

\section{INTRODUCTION}

During the past few decades, the development and professional use of tools to simulate the transfer of heat, air and moisture (HAM) in building materials, building components, building zones and whole buildings have progressively increased. Currently, researchers are striving to advance the integrated simulation of the HAM conditions in building zones and building components in response to the interior and exterior climatic loads. The main requirement for successful modelling of the hygrothermal interactions between building components and building zones is the correct treatment of the interfacial flows at the boundaries [1].

The heat, air and moisture conditions in a building component are dependent on the boundary conditions, i.e. the indoor and outdoor climate conditions. The temperature and relative humidity in the air near to the building component are seldom uniform: spatial and temporal variations are due to local and variable heat and moisture sources, imperfect mixing and microclimatic effects. The convective heat and moisture transfer coefficients similarly vary in space and time due to their strong dependence on for example the local air velocity and the local temperature. These local indoor environmental conditions and surface transfer coefficients however can be very important with respect to the hygrothermal response of building components [2] [3] [4], annual heating load predictions of a building [5], local microclimatic conditions [6], heat and moisture buffering of interior finishes [4] [6] [7], historic brick wall buildings [8], and conservation of culturally valuable objects in historical buildings [9].

For that reason, recent progress has focused on integrated HAM building simulation models, by the coupling of building zone airflow models with building component HAM models. Computational fluid dynamics models [6] [9] and sub-zonal airflow models [10] have been used to model the local indoor environmental conditions and convective surface transfer coefficients. Computational Fluid Dynamics (CFD) models are capable of predicting the local temperature and vapour content near a building component as well as the local surface transfer coefficients. However, such detailed airflow models cannot easily and quickly solve transient hygrothermal interactions across the boundaries of a HAM building model. In practice, only steady-state simulations of the airflow in a single room at a specific time, and/or transient simulations over a relatively short period of time are feasible. As these CFD calculations are relatively computationally intensive, transient calculations over a longer period of time are currently not possible. However, some of the significant transport processes involved, such as moisture transport in building components, are fundamentally dominated by their transient nature.

As an alternative to the use of CFD models, which are strongly limited by computer capacity, subzonal airflow models can be used to describe the airflow in building zones or parts of building zones. Comprehensive reviews of the literature on sub-zonal models have been carried out by Teshome and Haghighat [11], and Megri and Haghighat [12]. Their evaluations focused on the developments and applications over the last three decades. Applications have shown that the sub-zonal modelling approach can be a suitable method to estimate temperature and relative humidity fields in a room with reasonable accuracy. Sub-zonal models can moreover give a satisfactory estimate of airflow patterns, but not highly detailed information on air flow velocities. Nonetheless, this approach has been shown to adequately estimate (annual) indoor thermal comfort [13]. However, it has remained undetermined whether these models can provide reliable and accurate predictions of the local indoor environmental conditions and the local convective surface transfer coefficients compared to CFD.

The objective of this study was to investigate the applicability of the sub-zonal model for transient HAM building simulations, focusing on two requirements:

1. The accurate prediction of the local indoor environmental conditions near the building components.

2. The accurate prediction of the local convective surface transfer coefficients at building component surfaces.

\section{Method}

The methodology which has been applied was as follows: two test cases for respectively natural and forced convection in a building zone were selected for analysis. The indoor environmental conditions in the zone were simulated using a sub-zonal airflow model, in combination with different convective surface 
Postprint: Steskens PWMH, Janssen H, Rode C, 2013. Evaluation of sub-zonal air flow models for the prediction of local interior boundary conditions - natural and forced convection cases, Indoor and Built Environment,22:395-409.

transfer coefficient models, describing the convective surface heat and moisture transfer coefficients along the walls in the room. The local temperature and vapour content distributions near the walls predicted by the sub-zonal airflow models were compared to experimental results and numerical results obtained from CFD. Moreover, the predicted surface transfer coefficients were compared with numerical results from CFD.

In a first section, the selected two cases are presented in more detail. The following section introduces the numerical modelling, particularly the sub-zonal HAM model and the surface transfer coefficient models. The evaluation and comparison of experimental and numerical results is brought forward in the key section of the paper, which is then finalised with the conclusions.

\section{SELECTED CASES}

Two cases considering air flow in building zones form the basis of the analysis: one case focused on natural convection, while the other considered forced convection. For natural convection, experimental results from the MINIBAT test cell at CETHIL (Thermal Sciences Research Center of Lyon) [14] were used; for forced convection, measured data for the Annex 20 Benchmark [15] are applied. Moreover, sub-zonal simulation results are confronted with reference solutions for the temperature and vapour content distribution and the local convective surface transfer coefficients obtained from CFD simulations. The results from the CFD simulation have been verified and validated based on the work published by Steeman [9], by Chen [16] and by Nielsen [15]. The CFD results moreover agree well with the experimental results. As it is not the focus of the current work to give an intensive validation of the CFD simulation, a detailed verification of the CFD results was omitted.

\section{Natural convection: MINIBAT}

The MINIBAT test cell is a room designed to study the airflow in the room under laboratory conditions. A detailed description of the MINIBAT test cell can be found in [17]. The MINIBAT test cell was a $24 \mathrm{~m}^{3}(3.1 \times 3.1 \times 2.5 \mathrm{~m})$ single volume with controlled surface temperatures. The temperatures of the walls (on the right and left hand side, Figure 1) and of the floor and ceiling were kept constant at $33.0^{\circ} \mathrm{C}$, $16.9^{\circ} \mathrm{C}, 26.9^{\circ} \mathrm{C}$, and $28.5^{\circ} \mathrm{C}$ respectively. The temperature of the two other walls was approximately $27^{\circ} \mathrm{C}$. As a similar surface temperature was applied on these walls, the airflow in the centre of the room can be considered two-dimensional. The analysis here focused on the symmetry plane. Figure 1 presents a twodimensional vertical section through the room along the symmetry plane, and the corresponding geometry and boundary conditions. The relative humidity at both wall surfaces was $50 \% \mathrm{RH}$, while the floor and ceiling were vapour tight.

Inard et al. [14] carried out measurements of the natural convective air flow in the room, to validate and verify numerical results from a sub-zonal model. Detailed experimental information is available regarding the airflow pattern and temperature distribution in the MINIBAT test cell under specific conditions. The data was used for comparison with the results obtained in the present study. 
Postprint: Steskens PWMH, Janssen H, Rode C, 2013. Evaluation of sub-zonal air flow models for the prediction of local interior boundary conditions - natural and forced convection cases, Indoor and Built Environment,22:395-409.

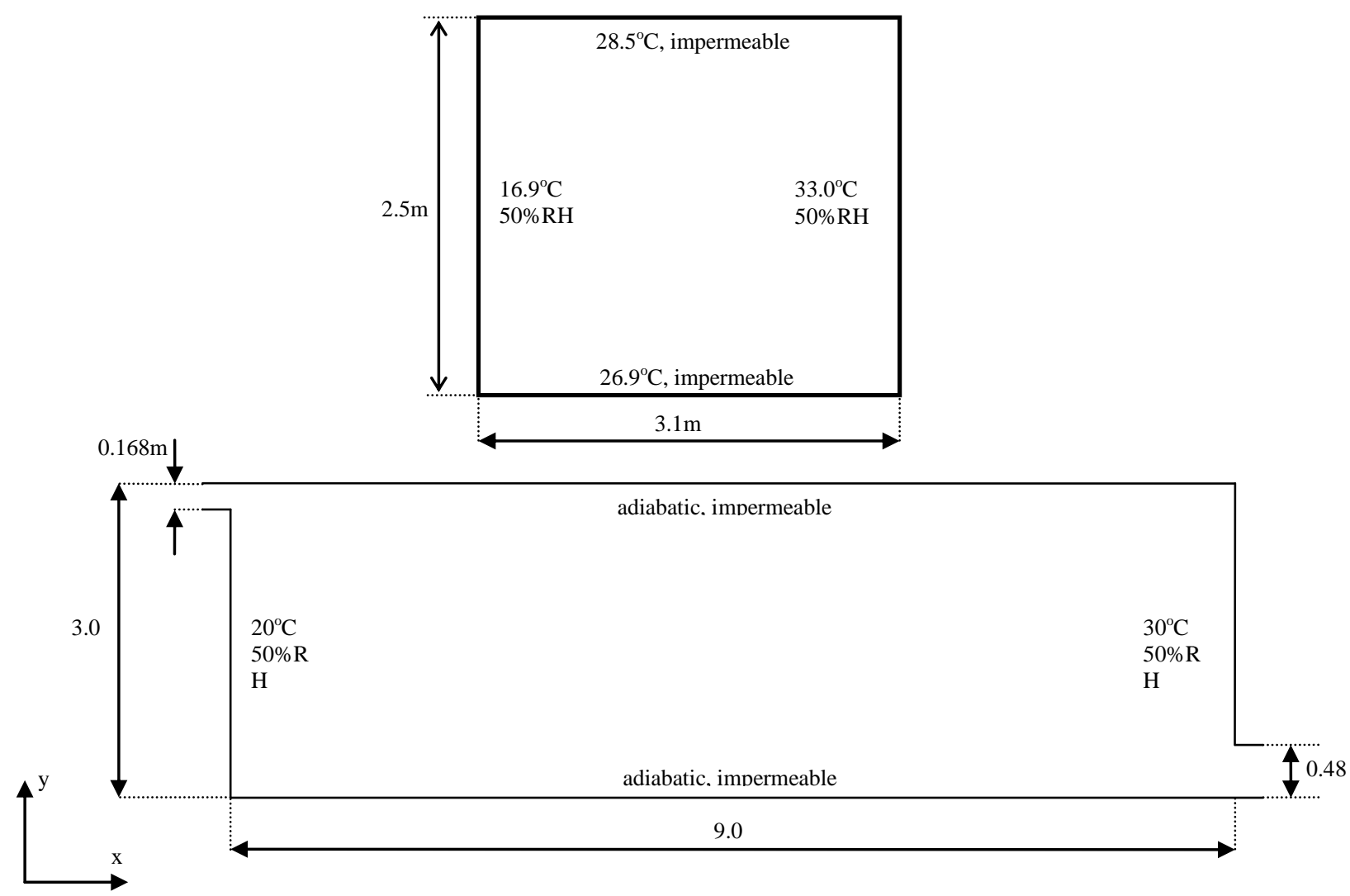

Figure 1: Vertical section of the investigated cases showing the geometry and boundary conditions for the MINIBAT test cell (top), and the Annex 20 Benchmark (bottom).

\section{Forced convection: Annex 20}

Within the framework of the International Energy Agency project Annex 20 'Air flow patterns within buildings', a two dimensional test case has been specified in [15]. Detailed experimental data is thus available. The configuration of the room is shown in Figure 1. The room is specified by the room length of $9.0 \mathrm{~m}$ and height $3.0 \mathrm{~m}$. The other dimensions are the height of the air inlet opening of $0.168 \mathrm{~m}$, and the outlet opening of $0.48 \mathrm{~m}$. At the inlet the Reynolds number is 5000 and the turbulence intensity 4 , which corresponds to an inlet velocity of $0.455 \mathrm{~m} / \mathrm{s}$ and the inlet temperature is $15^{\circ} \mathrm{C}$. The room is ventilated with an air change rate of $14 \mathrm{~h}^{-1}$. Nielsen [18] carried out experiments in the facility and this data set has been used for the validation and verification of CFD results by Chen [16]. The experimental investigations from Nielsen [15] showed that the airflow in the centre of the enclosure can be considered to be two-dimensional. This assumption was applied in the present study. However, the original boundary conditions that were applied in the original Annex 20 Benchmark case were changed: the temperature and relative humidity at the surface of the left and right walls were $20^{\circ} \mathrm{C}$ and $50 \%$, and $30^{\circ} \mathrm{C}$ and $50 \%$ respectively. Originally, isothermal and non-isothermal cases have been applied in the Annex 20 Benchmark case. For additional information, the reader is referred to [15] and [16]. The ceiling and floor were assumed to be adiabatic and impermeable.

\section{NUMERICAL MODELLING}

For each test case, several sub-zonal airflow models have been developed and simulated to predict the heat and moisture flows in the room and the flows between the room and the building components. The results from the sub-zonal airflow model have been used for the prediction of the local convective surface transfer coefficients along the building components. Similarly, CFD simulations have been carried out for the prediction of the indoor environmental conditions and surface transfer coefficients in each test case. The CFD simulations have been performed within the framework of the present study and carried out along the best practice guidelines that were presented by Steeman [9]. 
Postprint: Steskens PWMH, Janssen H, Rode C, 2013. Evaluation of sub-zonal air flow models for the prediction of local interior boundary conditions - natural and forced convection cases, Indoor and Built Environment,22:395-409.

\section{Sub-zonal air, heat and moisture model}

The airflow in the building zone was modelled using a sub-zonal airflow model. The zone was subdivided into a relatively small number of discrete sub-zones, typically less than 1000 for a three-dimensional case. Within a sub-zone, the temperature and relative humidity were considered to be uniform.

In sub-zonal airflow models the airflow is governed by a relatively simple set of equations compared to CFD models. The steady-state air mass balance of each sub-zone $\Omega$, with velocity components $u\left[\mathrm{~m} \mathrm{~s}^{-1}\right]$, in a fluid of density $\rho\left[\mathrm{kg} \mathrm{m}^{3}\right]$ at temperature $T[\mathrm{~K}]$, is governed by Equation (1).

$\int_{\Omega}\left\{\rho(\nabla \cdot u)+S_{\rho}\right\} d \Omega$

where $S_{\rho}$ is a source term $\left[\mathrm{kg} \mathrm{m}^{-3} \mathrm{~s}^{-1}\right]$. Density variations of the air are modelled using the incompressible ideal gas relationship.

The steady-state energy balance in the sub-zone $\Omega$ is expressed by Equation (2).

$\int_{\Omega}\left\{\nabla \cdot\left(\rho c_{p} T u\right)-\nabla \cdot(\lambda \nabla T)+S_{T}\right\} d \Omega$

where $c_{p}$ is the specific heat capacity $\left[\mathrm{J} \mathrm{kg}^{-1} \mathrm{~K}^{-1}\right], \lambda$ is the thermal conductivity of the fluid [ $\mathrm{W} \mathrm{m}^{-1} \mathrm{~K}^{-1}$ ], while $S_{T}$ represents any heat sources $\left[\mathrm{W} \mathrm{m}^{-3}\right]$ in the fluid.

Similarly, the steady-state vapour mass balance of each sub-zone is presented by Equation (3).

$\int_{\Omega}\left\{\nabla \cdot(\rho u x)-\nabla \cdot\left(\rho \mathrm{D}_{\mathrm{v}} \nabla x\right)+S_{v}\right\} d \Omega$

where $x$ is the vapour content per kg dry air $\left[\mathrm{kg} \mathrm{kg}^{-1}\right]$, and $D_{v}$ is the vapour diffusivity $\left[\mathrm{m}^{2} \mathrm{~s}^{-1}\right]$. Vapour sources in the room are represented by the source term $S_{v}\left[\mathrm{~kg} \mathrm{~m}^{-3} \mathrm{~s}^{-1}\right]$.

With respect to the boundary conditions, the heat transfer to the building component from the air near to the component is represented as a source term (Equation (4)).

$\int_{\Omega} S_{T} d \Omega=\int_{A}\left\{n \cdot\left(\alpha_{c}\left(T_{\text {air }}-T_{\text {wall }}\right)\right)\right\} d A$

where $\alpha_{c}$ is the convective surface heat transfer coefficient [ $\left.\mathrm{W} \mathrm{m}^{-2} \mathrm{~K}^{-1}\right], T$ and $T_{\text {wall }}$ are the air temperature in the centre of the sub-zonal cell adjacent to wall and the wall surface temperature $[\mathrm{K}]$ respectively, and $A$ is the surface $\left[\mathrm{m}^{2}\right]$, corresponding to the height or the width of the control volume.

The boundary conditions for vapour transfer to the building component from the air adjacent to the component are represented as a source term:

$\int_{\Omega} S_{M} d \Omega=\int_{A} n \cdot\left(\beta_{X}\left(x_{\text {air }}-x_{\text {wall }}\right)\right) d A$

where $\beta_{X}$ is the surface moisture transfer coefficient $\left[\mathrm{m} \mathrm{s}^{-1}\right], x$ and $x_{\text {wall }}$ are vapour content of the air in the centre of the sub-zonal cell adjacent to wall and at the wall surface $\left[\mathrm{kg} \mathrm{kg}^{-1}\right]$ respectively, and $A$ is the surface $\left[\mathrm{m}^{2}\right]$, corresponding to the height and width of the control volume.

An upwind scheme was applied for the discretization of the resulting system of equations. The airflow model was implemented in the CHAMPS-BES program [19], which is an envelope model for the coupled simulation of heat, air, moisture, and pollutant transport in building components.

The reader should notice that long-wave radiation among the surfaces in the zone is neither considered in the CFD models nor in the sub-zonal models. This may result in deviations between the results, when comparing experiments and simulation. The modelling of thermal radiation in CFD and sub-zonal models would require the implementation and application of two different radiation models. In general, CFD software incorporates specific models for thermal radiation, for example the Rosseland radiation model [20], while other models are available for the implementation in sub-zonal models. The use of different radiation models may result in deviations between the CFD results and the sub-zonal model's results caused by the radiation models. Since 
Postprint: Steskens PWMH, Janssen H, Rode C, 2013. Evaluation of sub-zonal air flow models for the prediction of local interior boundary conditions - natural and forced convection cases, Indoor and Built Environment,22:395-409.

it is not the objective of the present study to investigate the performance of the different radiation models, this analysis is not included in this paper.

\section{Flow element sub-zones}

If a sub-zone is under direct influence of a flow driver, for example a fan or a heater, and forced convection may be important; the flow in the sub-zone is modelled as a flow element. Flow elements are treated as isolated volumes where the air movement is controlled by a restricted number of parameters, and the air movement is fairly independent of the general flow in the enclosure. Often, the mathematical equations governing the airflow in flow elements are based on empirical relationships [14] [21] [22]. In this study, a thermal boundary layer model is used, based on experimental work that has focused on the analysis of the thermal boundary layer along flat plates and a jet model. For additional information with respect to the models describing the airflow in the flow elements, the reader is referred to [23].

\section{Local convective heat transfer coefficients Literature}

Different models for the local convective surface heat and moisture transfer coefficients, $\alpha_{c}$ and $\beta_{X}$ respectively, are applied. The relationships are determined analytically, experimentally, or numerically. The models result from a review of the literature on convective heat transfer coefficient modelling. The models are characterized by the different flow regimes in a room.

The local convective heat transfer along a vertical wall $\left(\alpha_{c}\left[\mathrm{~W} \mathrm{~m}{ }^{-2} \mathrm{~K}^{-1}\right]\right)$ is then defined by the local Nusselt number (Equation 6).

$\alpha_{c}=\frac{N u_{y}}{y}$

where $N u_{y}$ is the local Nusselt number along the building component, $\lambda$ is the thermal conductivity of the fluid $\left[\mathrm{W} \mathrm{m}{ }^{-1} \mathrm{~K}^{-1}\right]$, and $y$ is the coordinate along the component $[\mathrm{m}]$.

Table 1 presents the convective surface heat transfer coefficient models which are applied, where $G r_{y}$ represents the local Grashof number [-], $P r$ the Prandtl number for air [-], and $R a_{y}$ the local Rayleigh number [-]. The table shows that three different models for the Convective Heat Transfer Coefficient (CHTC) are applied: a theoretical model (1) based on the boundary layer theory describing the natural convective airflow along a vertical flat plate with uniform surface temperature [24], and two experimentally based models, respectively models (2) and (3). The models have been implemented and the predicted CHTCs are compared with CFD predictions and average convective surface transfer coefficients obtained from literature [5].

Similarly as for natural convection, relationships for the local CHTC for forced convection are applied: models based on the correlations for laminar forced convection along a vertical plate with a uniform surface temperature, developed by Churchill [24] (1), and Rose [24] (2). Those correlations have been determined for local Reynolds numbers smaller than the critical Reynolds number of 50,000. Churchill and Ozoe [25] (3) extended these correlations for transitional and turbulent boundary layers. Table 2 presents an overview of the relationships that are applied in the present study, where $R_{x}$ is the local Reynolds number along the plate, and $\operatorname{Pr}$ is the Prandtl number.

It should be noticed that these correlations have been determined in laboratory conditions for specific boundary conditions, such as a uniform surface temperature, and other assumptions. These relationships may have limitations with respect to the applications to building components, where the airflow is also influenced by the geometry of the enclosure, for example corners. These correlations may fail to give accurate predictions of the local convective surface transfer coefficients. Therefore, the study also focused on alternative methods to obtain reliable predictions of the convective surface transfer coefficients.

\begin{tabular}{|l|l|l|l|}
\hline CHTC Model & Source & \multicolumn{2}{|c|}{} \\
\hline $\begin{array}{l}\text { 1 Flat plate } \\
\text { Schlichting and } \\
\text { Gersten 2003) }\end{array}$ & Theory & $\begin{array}{l}\text { Laminar } \\
\left(\mathrm{Gr}_{\mathrm{y}}<1 \cdot 10^{9}\right)\end{array}$ & $N u_{y}=\frac{0.676 \operatorname{Pr}^{1 / 2}}{(0.861+\mathrm{Pr})^{1 / 4}}\left(\frac{G r_{y}}{4}\right)^{1 / 4}$ \\
\hline
\end{tabular}


Postprint: Steskens PWMH, Janssen H, Rode C, 2013. Evaluation of sub-zonal air flow models for the prediction of local interior boundary conditions - natural and forced convection cases, Indoor and Built Environment,22:395-409.

\begin{tabular}{|l|l|l|l|}
\hline & & $\begin{array}{l}\text { Turbulent } \\
\left(\mathrm{Gr}_{\mathrm{y}}>1 \cdot 10^{10}\right)\end{array}$ & $N u_{x}=0.0295\left(G r_{y}\right)^{2 / 5}(\operatorname{Pr})^{7 / 15}\left(1+0.494 \operatorname{Pr}^{2 / 3}\right)^{-2 / 5}$ \\
\hline $\begin{array}{l}\text { 2 Turner and } \\
\text { Flake 1980 }\end{array}$ & Exp. & $\begin{array}{l}3.5 \cdot 10^{6}<\mathrm{Ra}< \\
5.5 \cdot 10^{9}\end{array}$ & $N u_{y}=0.524\left(G r_{y}\right)^{0.26}$ \\
\hline $\begin{array}{l}\text { 3 Bohn et al. } \\
1984\end{array}$ & Exp. & $\begin{array}{l}3 \cdot 10^{9}<\mathrm{Ra}< \\
6 \cdot 10^{10}\end{array}$ & $N u_{y}=0.62\left(R a_{y}\right)^{1 / 4}$ \\
\hline
\end{tabular}

Table 1: Local CHTC Models for natural convection along a vertical wall

\begin{tabular}{|c|c|c|}
\hline $\begin{array}{l}\text { CHTC } \\
\text { Model }\end{array}$ & & \\
\hline $\begin{array}{l}\text { 1Flat plate } \\
\text { (Churchill) } \\
\text { [50] }\end{array}$ & Laminar & $N u_{x}=\frac{0.3387 \mathrm{Re}_{x}^{0.5} \operatorname{Pr}^{0.33}}{\left[1+\left(\frac{0.0468}{\operatorname{Pr}}\right)^{0.667}\right]^{0.25}}$ \\
\hline $\begin{array}{l}2 \text { Flat plate } \\
\text { (Rose) [50] }\end{array}$ & & $N u_{x}=\frac{\operatorname{Re}_{x} \operatorname{Pr}^{0.5}}{\left[27.8+75.9 \operatorname{Pr}^{0.306}+657 \operatorname{Pr}\right]^{0.1667}}$ \\
\hline $\begin{array}{l}3 \text { Flat plate } \\
\text { (Churchill } \\
\text { and Ozoe) } \\
{[60]}\end{array}$ & $\begin{array}{l}\text { Laminar } \\
\operatorname{Re}_{\mathrm{x}}<\operatorname{Re}_{\mathrm{cr}}\end{array}$ & $N u_{x}=\frac{0.886 \operatorname{Re}_{x}^{0.5} \operatorname{Pr}^{0.33}}{\left[1+\left(\frac{\operatorname{Pr}}{0.0207}\right)^{0.667}\right]^{0.25}}$ \\
\hline & $\begin{array}{l}\text { Transition } \\
\operatorname{Re}_{\mathrm{cr}}<\operatorname{Re}_{\mathrm{x}}<10^{7}\end{array}$ & $N u_{x}=0.0296 \operatorname{Re}_{x}^{0.8} \operatorname{Pr}^{0.33}$ \\
\hline & $\begin{array}{l}\text { Turbulent } \\
\text { Rex }>10^{7}\end{array}$ & $N u_{x}=1.596 \operatorname{Re}_{x}\left(\ln \left(\operatorname{Re}_{x}\right)\right)^{-2.584} \operatorname{Pr}^{0.33}$ \\
\hline $\begin{array}{l}\text { 4 Local } \\
\text { Beausoleil- } \\
\text { Morrison } \\
\{\{505 \\
\text { Beausoleil- } \\
\text { Morrison, I. } \\
2000 ;\}\}\end{array}$ & & $N u_{x}=\frac{x}{\lambda}\left(\frac{T_{s}-T_{f}}{\Delta T}\right) \cdot\left[-0.199+0.19\left(A C H \cdot\left(\frac{\Delta h}{H}\right)\right)^{0.8}\right]$ \\
\hline
\end{tabular}

Table 2: Local CHTC models for forced convection

\section{From local relationships to global relationships}

In this paper, two approaches for modelling of the convective transfer coefficient have been investigated. A first approach was the prediction of the local convective surface transfer coefficients based on the local conditions in the room. The main limitation of this approach is that the prediction of the local transfer coefficients is strongly dependent on the local conditions predicted by the sub-zonal model. Hence, several studies reported in literature already showed that the sub-zonal airflow model may be less reliable with respect to the prediction of local conditions in a room, but still provide accurate predictions of the global conditions in the room. Therefore, a second approach has been applied which is based on the predicted global conditions in the room. The main advantage of such an approach would be that the predicted convective surface transfer coefficients are less dependent on the accuracy of the sub-zonal airflow model.

A literature study showed that such relationships have not been extensively documented. Correlations for average (global) surface transfer coefficients for an entire building component have only been reported by Beausoleil-Morrison [5]. Within the framework of this study, several methods and approaches have been investigated. The method that generally gives the most accurate prediction of the 
Postprint: Steskens PWMH, Janssen H, Rode C, 2013. Evaluation of sub-zonal air flow models for the prediction of local interior boundary conditions - natural and forced convection cases, Indoor and Built Environment,22:395-409.

convective surface transfer coefficients for forced convection along a building component is presented in this paper. The approach is based on the relationships developed by Beausoleil-Morrison [5].

The uniform relationships developed by Beausoleil-Morrison [5] are transformed into local relations by means of an alternative approach. For an entire building surface, the global CHTC for forced convection is represented by Equation (7)

$\alpha_{c, f}=\left(\frac{T_{s}-T_{f}}{\Delta T}\right) \cdot\left[-0.199+0.19(A C H)^{0.8}\right]$

where $\alpha_{c, f}$ is the convective surface transfer coefficient for forced convection [ $\mathrm{W} \mathrm{m}^{-2} \mathrm{~K}^{-1}$ ], $T_{s}$ is the surface temperature $[\mathrm{K}], T_{f}$ is the temperature of the air at the air inlet $[\mathrm{K}], \Delta T$ is the absolute temperature difference between the air in the room and the building surface $[\mathrm{K}]$, and ACH is the air change rate of the room $\left[\mathrm{h}^{-1}\right]$. The correlation presented by Equation (7) has been 'localized' by scaling for application to a single subzone, resulting in Equation (8).

$\alpha_{c, f}=\left(\frac{T_{y, s}-T_{y, f}}{\Delta T}\right) \cdot\left[-0.199+0.19\left(A C H \cdot\left(\frac{\Delta h}{H}\right)\right)^{0.8}\right]$

where $\alpha_{c, f}$ is the local convective surface transfer coefficient for forced convection [ $\mathrm{W} \mathrm{m}^{-2} \mathrm{~K}^{-1}$ ], $T_{y, s}$ is the local surface temperature $[\mathrm{K}]$ of the building component, $T_{y, f}$ is the local temperature of the air in the room $[\mathrm{K}]$ near the component, $\Delta T$ is the absolute temperature difference between the air in the room and the building surface $[\mathrm{K}], A C H$ is the air change rate of the subzone $\left[\mathrm{h}^{-1}\right], \Delta h$ is the height of the sub-zone [m], and $H$ is the height of the building component or room height [m].

The reader should notice that the relationship for the convective surface transfer coefficient presented by Equation (8) has been developed empirically, and generally gives the best results when compared to the surface transfer coefficients predicted by CFD.

\section{Local convective moisture transfer coefficients}

The moisture fluxes between the room and the building component were modelled using the Chilton-Colburn analogy (Equation (9)) [26], which relates the heat and mass transfer coefficients directly.

$\frac{\alpha_{c}}{\beta_{X}}=\rho c_{\mathrm{p}}\left(\frac{\mathrm{Sc}}{\operatorname{Pr}}\right)^{2 / 3}=\rho \mathrm{c}_{\mathrm{p}}\left(\frac{\mathrm{D}_{\mathrm{T}}}{\mathrm{D}_{\mathrm{v}}}\right)^{2 / 3}=\rho \mathrm{c}_{\mathrm{p}} \mathrm{Le}^{2 / 3}$

where Le [-] is the Lewis number, defined as the ratio of thermal diffusivity $D_{T}\left[\mathrm{~m}^{2} \mathrm{~s}^{-1}\right]$ to mass diffusivity $D_{v}$ $\left[\mathrm{m}^{2} \mathrm{~s}^{-1}\right]$. Local convective surface heat transfer coefficients are obtained from the convective heat transfer coefficient models resulting in local convective surface moisture transfer coefficients.

The validity of the heat and mass analogy for airflows inside buildings has been studied by Steeman [9]. Despite the frequent use of the heat and mass transfer analogy, the author investigated whether the relationship is applicable for the determination of average and local convective surface mass transfer coefficients inside buildings, where natural and mixed convection occurs over complex geometries. For the scenarios with simultaneous heat and mass transfer, the research [9] produced good results and proved the capability of the heat and mass transfer analogy to accurately predict mass transfer coefficients for natural and mixed convection in these cases. Steeman also showed that problems can arise due to the choice of the reference condition, especially considering the cases with non-analogous boundary conditions for heat and mass transport.

In practical cases, the requirement that all boundary conditions for heat and mass transfer inside buildings should be analogous is rarely fulfilled. If the boundary conditions are not analogous, the accurate prediction of local mass fluxes using the analogy is no longer guaranteed when one single reference value is used. A more intensive examination of the study [9] showed that it is not necessarily required to discard the Chilton-Colburn analogy, but then computational fluid dynamics should be used to choose the correct reference condition for the analogy. In this way, the determination of local surface mass transfer coefficient in case of non-analogous boundary conditions by means of the Chilton-Colburn analogy is applicable, but should be done carefully. For additional information on the validity of the Chilton-Colburn analogy in buildings, the reader is referred to the work presented by Steeman [9]. 
Postprint: Steskens PWMH, Janssen H, Rode C, 2013. Evaluation of sub-zonal air flow models for the prediction of local interior boundary conditions - natural and forced convection cases, Indoor and Built Environment,22:395-409.

\section{Results of the analysis}

Both cases were simulated using the presented sub-zonal airflow model, in combination with the presented convective surface transfer coefficient models. These simulation results were then compared with experimental and CFD results.

\section{Natural convection: MINIBAT}

The results from the sub-zonal airflow model and the CFD results (Figure 2) were compared to the experimental (Error! Reference source not found.Figure 3). The following observations were made:

- Global distribution. The predicted temperature and vapour content distribution resulting from the measurements, CFD and the sub-zonal model are relatively similar. The models are capable of giving a relatively rough prediction of the stratification in the room. However, it should also be noticed that the simulated temperatures (both CFD and sub-zonal) deviate clearly from the measured temperatures. This deviation could be caused by the influence of radiation which has not been accounted for in the CFD and sub-zonal airflow models. Therefore, the analysis proceeds with the comparing the results from the CFD model and the sub-zonal model, i.e. an inter-model comparison.

- $\quad$ Near wall distribution. Both models are capable of predicting a stratified pattern in the room as Figure 4 shows.

Besides the local temperature and vapour content, the convective surface transfer coefficients are important for the prediction of the heat and moisture flows between the room and the walls. The sub-zonal model is used to model the natural convective airflow in the room. The results obtained from the sub-zonal airflow model were used as input data for the surface transfer coefficient models. The predicted convective heat and moisture transfer coefficients (CHTC and CMTC) along the walls resulting from the sub-zonal model and the CFD model were compared. Table 3 presents an overview of the simulated surface transfer coefficient models and computational grids that are used.

\begin{tabular}{|l|l|l|}
\hline MODEL & & Grid $(\mathrm{x} \cdot \mathrm{y})$ \\
\hline$($ ref $)$ & $\begin{array}{l}\text { Beausoleil-Morrison } \\
(2000)\end{array}$ & $8 \times 10$ \\
\hline (a) & Flat plate & $8 \times 10$ \\
\hline (b) & $\begin{array}{l}\text { Turner and Flake } \\
(1980)\end{array}$ & $8 \times 10$ \\
\hline (c) & $\begin{array}{l}\text { Turner and Flake } \\
(1980)\end{array}$ & $16 \times 20$ \\
\hline (d) & Bohn et al. (1984) & $8 \times 10$ \\
\hline
\end{tabular}

Table 3: Applied surface transfer coefficient models and corresponding computational grids (natural convection) 
Postprint: Steskens PWMH, Janssen H, Rode C, 2013. Evaluation of sub-zonal air flow models for the prediction of local interior boundary conditions - natural and forced convection cases, Indoor and Built Environment,22:395-409.
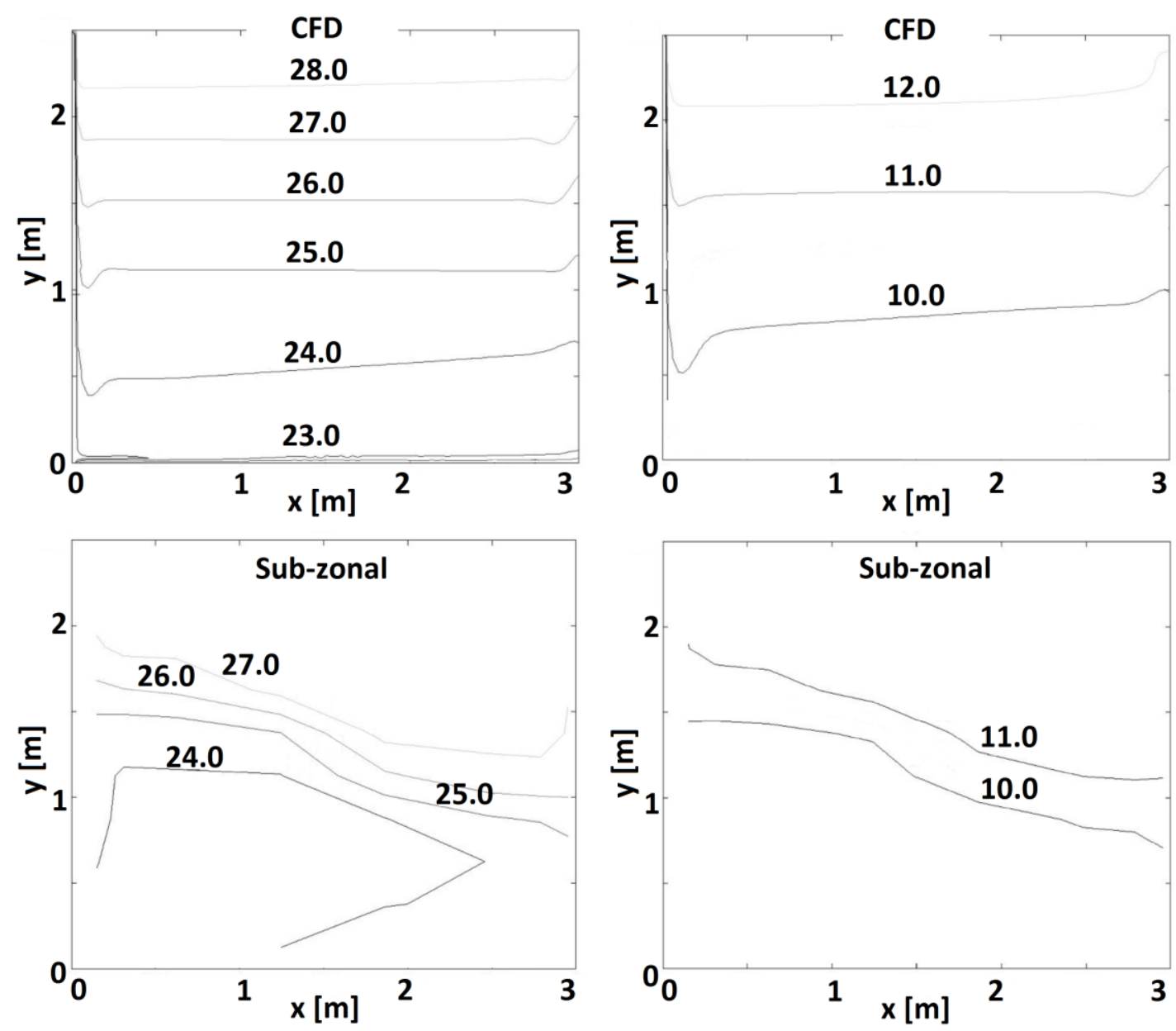

Figure 2: The predicted temperature distribution (left) and vapour content distribution (mass fraction, $x$ [ $g$ $\left.\mathrm{kg}^{-1}\right]$ ) (right) in the room obtained from CFD (top), and predicted by the sub-zonal model (bottom).

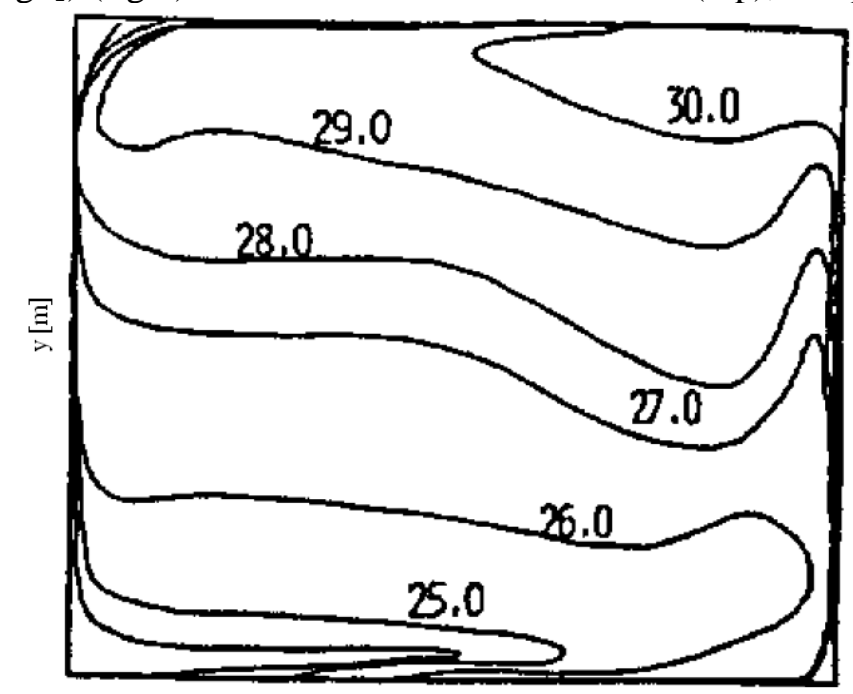

$\mathrm{x}[\mathrm{m}]$

Figure 3: Measured temperature distribution $\left[{ }^{\circ} \mathrm{C}\right]$ in the MINIBAT test cell [14]. 
Postprint: Steskens PWMH, Janssen H, Rode C, 2013. Evaluation of sub-zonal air flow models for the prediction of local interior boundary conditions - natural and forced convection cases, Indoor and Built Environment,22:395-409.
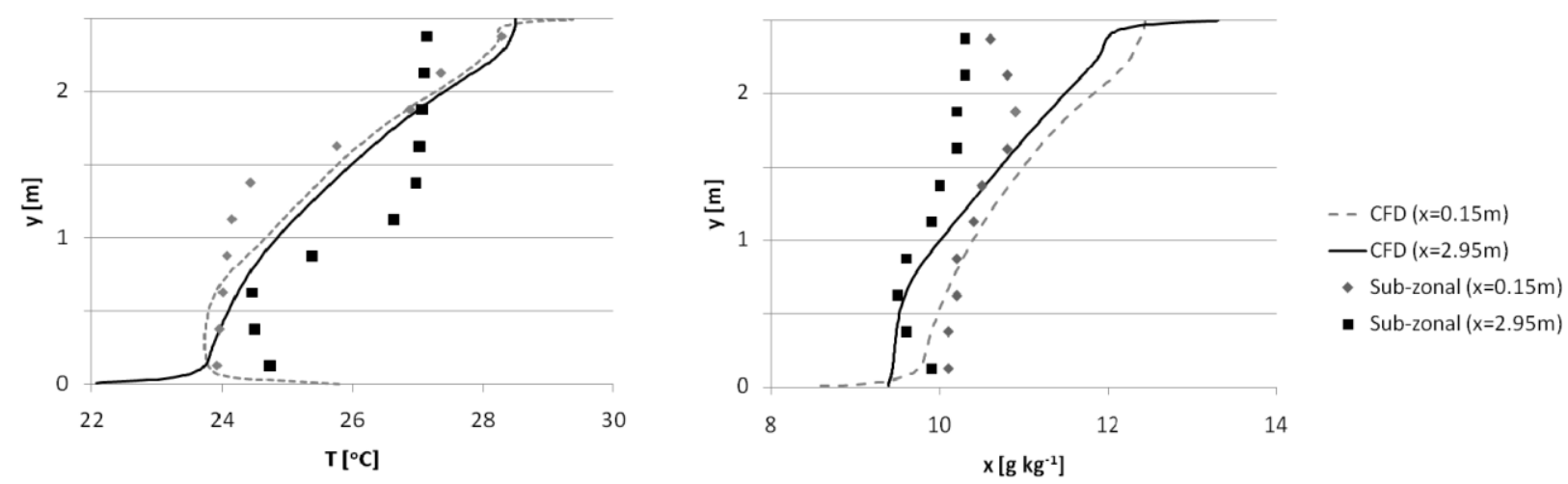

Figure 4: Temperature $\left[{ }^{\circ} \mathrm{C}\right]$ and vapour content $\left[\mathrm{g} \mathrm{kg}^{-1}\right]$ distribution at different locations in the room $(\mathrm{x}=0.15 \mathrm{~m}$ and $2.95 \mathrm{~m})$.
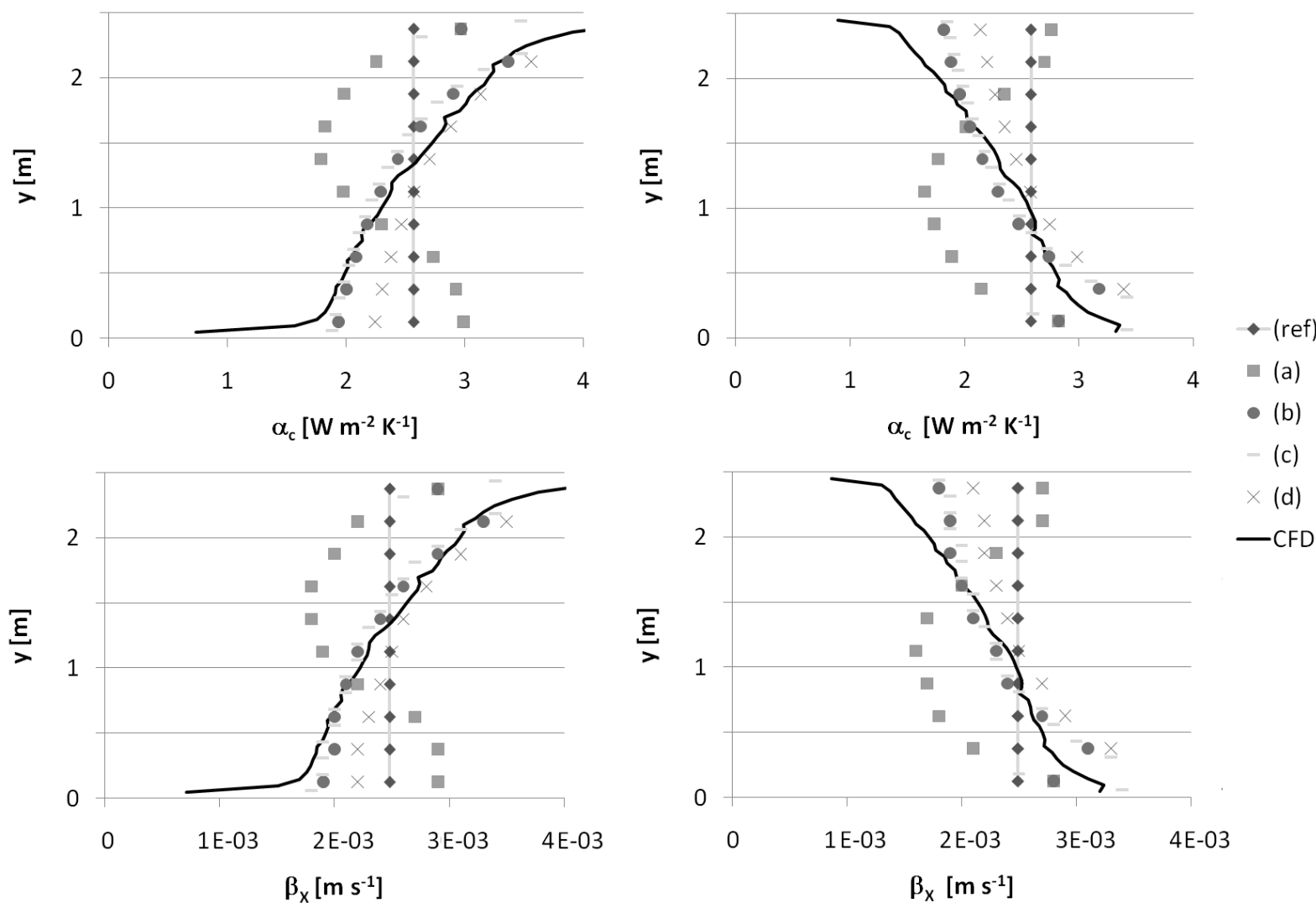

Figure 5: Convective surface heat transfer coefficient $\left(\alpha_{c}\left[\mathrm{~W} \mathrm{~m}^{-2} \mathrm{~K}^{-1}\right]\right)$ and convective surface moisture transfer coefficient $\left(\beta_{X}\left[\mathrm{~m} \mathrm{~s}^{-1}\right]\right)$ for the left wall (left) and the right wall (right).

Figure 5 presents a comparison of the local convective surface heat and moisture transfer coefficients resulting from the different convective transfer coefficient models and the values obtained from the CFD simulation. With respect to the coefficients predicted by model (a), based on the flat plate analogy, the figures show an under-prediction in the region from the leading corner down from/up to the centre of the wall $(\mathrm{y}=1.25 \mathrm{~m})$ and an over-prediction of the coefficients further from the centre $(\mathrm{y}=1.25)$. Comparison of the results with the CFD results showed that the main reason for the under/over prediction was that the size of the laminar region was over-predicted by the model, resulting in smaller surface transfer coefficients, while the size of the turbulent region was under-predicted. 
Postprint: Steskens PWMH, Janssen H, Rode C, 2013. Evaluation of sub-zonal air flow models for the prediction of local interior boundary conditions - natural and forced convection cases, Indoor and Built Environment,22:395-409.

Regarding the results predicted by model (b), (c), and (d), the resulting local surface transfer coefficients are comparable with the coefficients predicted by CFD. The transfer coefficients predicted by model (b) and (c), based on Turner and Flake (1980) [27], give the best agreement. Model (d) Bohn et al. (1984) [28] gave a slight over-prediction. This relatively high deviation might be caused by the dissimilarity between the simulated case and the conditions that have been used for the determination of the relationships. Bohn et al. (1984) [28] determined the CHTC for a cube, with a rib length of $0.3 \mathrm{~m}$, in water, and range of the Rayleigh number between $3 \cdot 10^{9}$ and $6 \cdot 10^{10}$, while Turner et al. (1980) determined the CHTC's for various rectangular boxes in air, and a range of the Rayleigh number between $3.5 \cdot 10^{6}$ and $5.5 \cdot 10^{9}$. The Rayleigh number in the studied room varied between $2.5 \cdot 10^{6}$ and $18 \cdot 10^{9}$.

The investigations showed that the surface transfer coefficient model based on the flat plate analogy is not suitable for the prediction of the convective surface transfer coefficients in the room. As has been discussed earlier, the specific assumptions of the boundary layer theory for flat plates, for example regarding the boundary conditions, geometrical influences, entrance velocity and leading edges, and surface roughness, are not (entirely) valid in building enclosures. Similar observations have been reported by Khalifa (2001) [29] and the authors concluded that a correlation obtained for an isolated flat plate is not suitable for a surface in a real sized enclosure, especially for buildings. This conclusion is confirmed by the present investigations. Furthermore, the boundary layer model that has been developed based on measurements of the global indoor environmental conditions for natural convection in a room, such as the model developed by Turner et al (1980) [27], are suitable for the prediction of the convective surface transfer coefficients, provided similar Rayleigh numbers are observed as in the experimental conditions on which the correlation is based.

\section{Forced convection: Annex 20}

Figure 6 shows the airflow pattern in the room predicted by CFD. The predicted temperature and vapour content distributions resulting from the sub-zonal model and CFD are compared. The following observations can be made:

- $\quad$ Global distribution: Comparing Figure 8 and Figure 9, it is observed that the sub-zonal is capable of giving a rough prediction of the global temperature and vapour content distribution in (the centre of) the room. However, discrepancies between the sub-zonal model and CFD with respect to the recirculation of the air are observed. Uniform temperature and vapour content distributions are observed in the main part of the room, where a large recirculation region of the air is present. In the corners, where a small recirculation region is present slightly higher temperatures are predicted. The sub-zonal model predicts a relatively uniform temperature and vapour content distribution in the entire room, as the model is not able to capture the local recirculation.

- Near wall distribution: The local temperature and vapour content distribution at $0.125 \mathrm{~m}$ from the walls is presented in Figure 9. Figure 9 shows that the temperature in the centre of the walls is predicted with a maximum deviation of around $1^{\circ} \mathrm{C}$. However, close to the floor and the ceiling, the relative deviation between the sub-zonal airflow model and CFD increases up to $3^{\circ} \mathrm{C}$. Similarly, the figure shows that the deviation increases up to $1.5 \mathrm{~g} / \mathrm{kg}$ with respect to the local vapour content in the corners. The local recirculation of the airflow shows to be a problem with respect to the prediction of the local quantities in the near-wall regions. 
Postprint: Steskens PWMH, Janssen H, Rode C, 2013. Evaluation of sub-zonal air flow models for the prediction of local interior boundary conditions - natural and forced convection cases, Indoor and Built Environment,22:395-409.

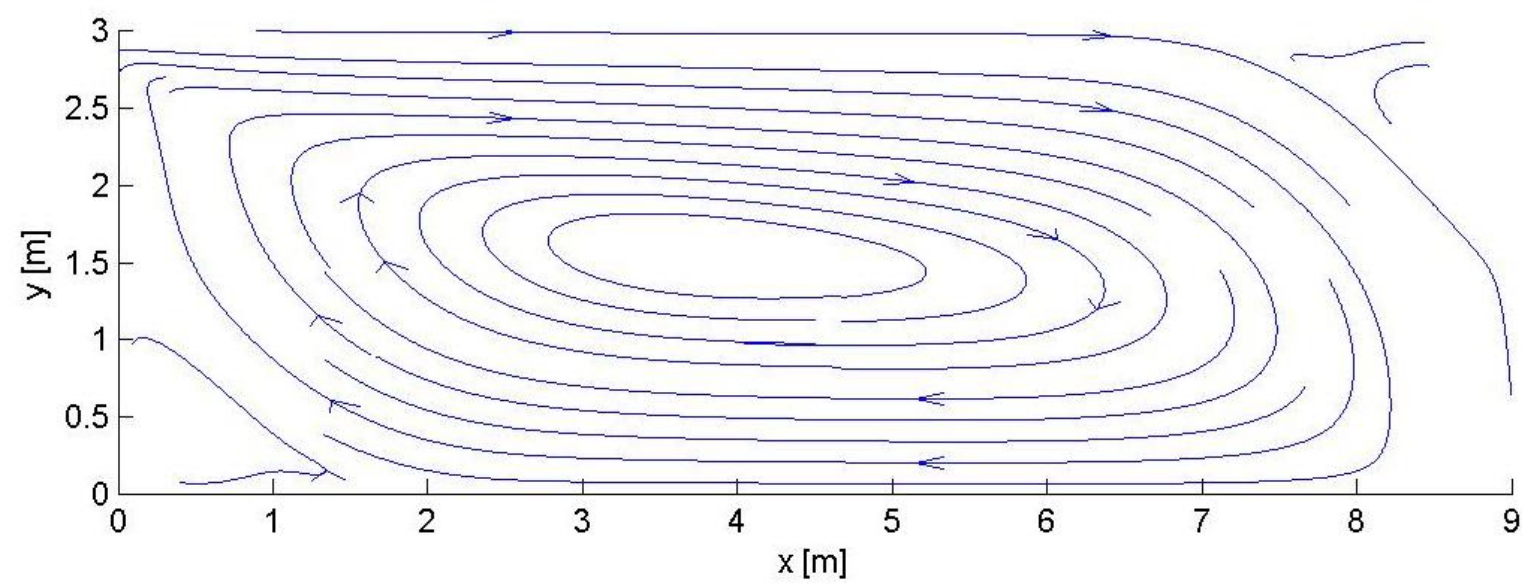

Figure 6: Air mass flow streamlines $\left[\mathrm{kg} \mathrm{s}^{-1}\right]$ resulting from the CFD simulation.
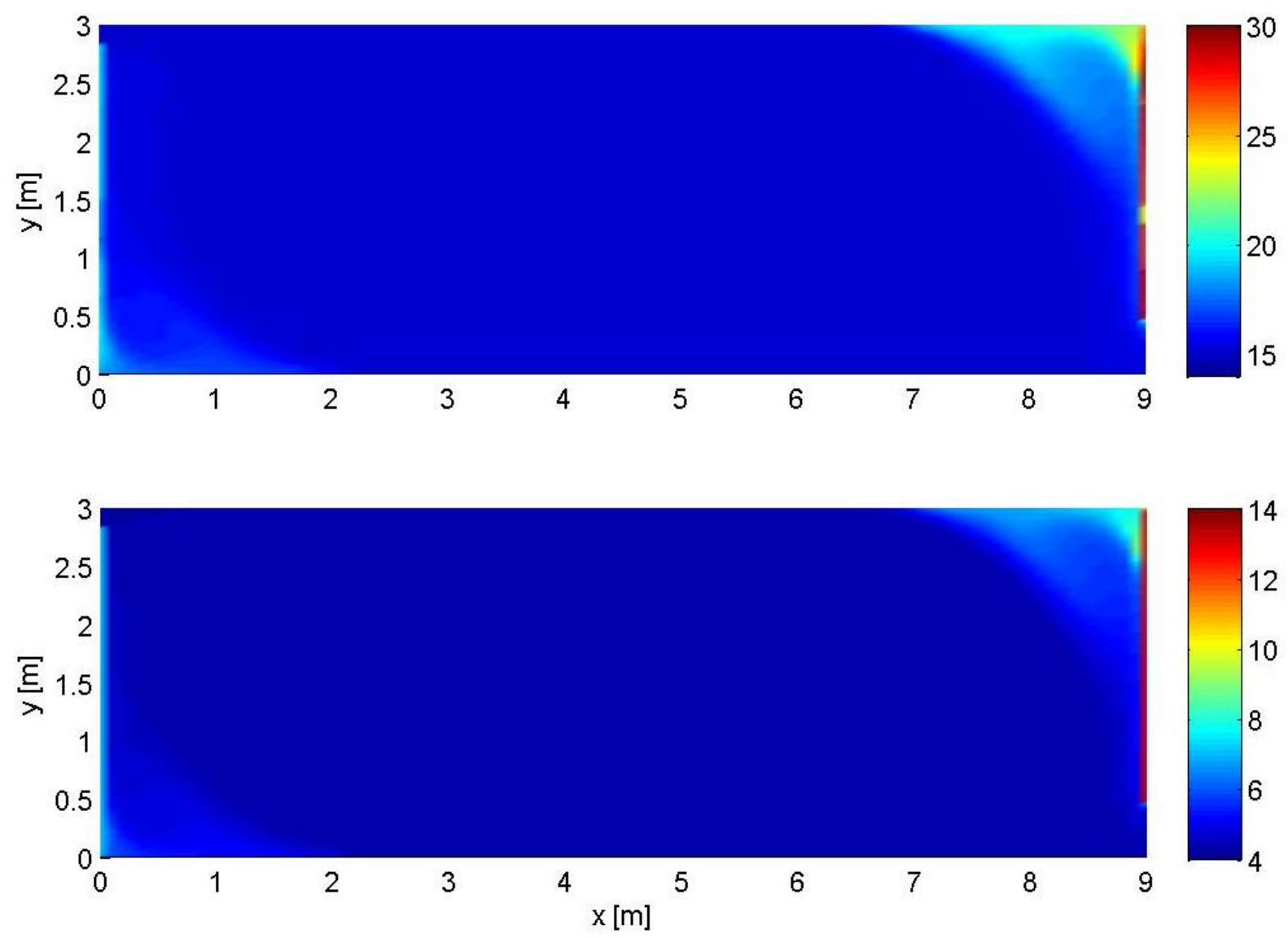

Figure 7: The predicted temperature distribution $\left[{ }^{\circ} \mathrm{C}\right]$ (top) and vapour content distribution (mass fraction, $\mathrm{x}$ $\left.\left[\mathrm{g} \mathrm{kg}^{-1}\right]\right)$ (bottom) in the room obtained from CFD. 
Postprint: Steskens PWMH, Janssen H, Rode C, 2013. Evaluation of sub-zonal air flow models for the prediction of local interior boundary conditions - natural and forced convection cases, Indoor and Built Environment,22:395-409.
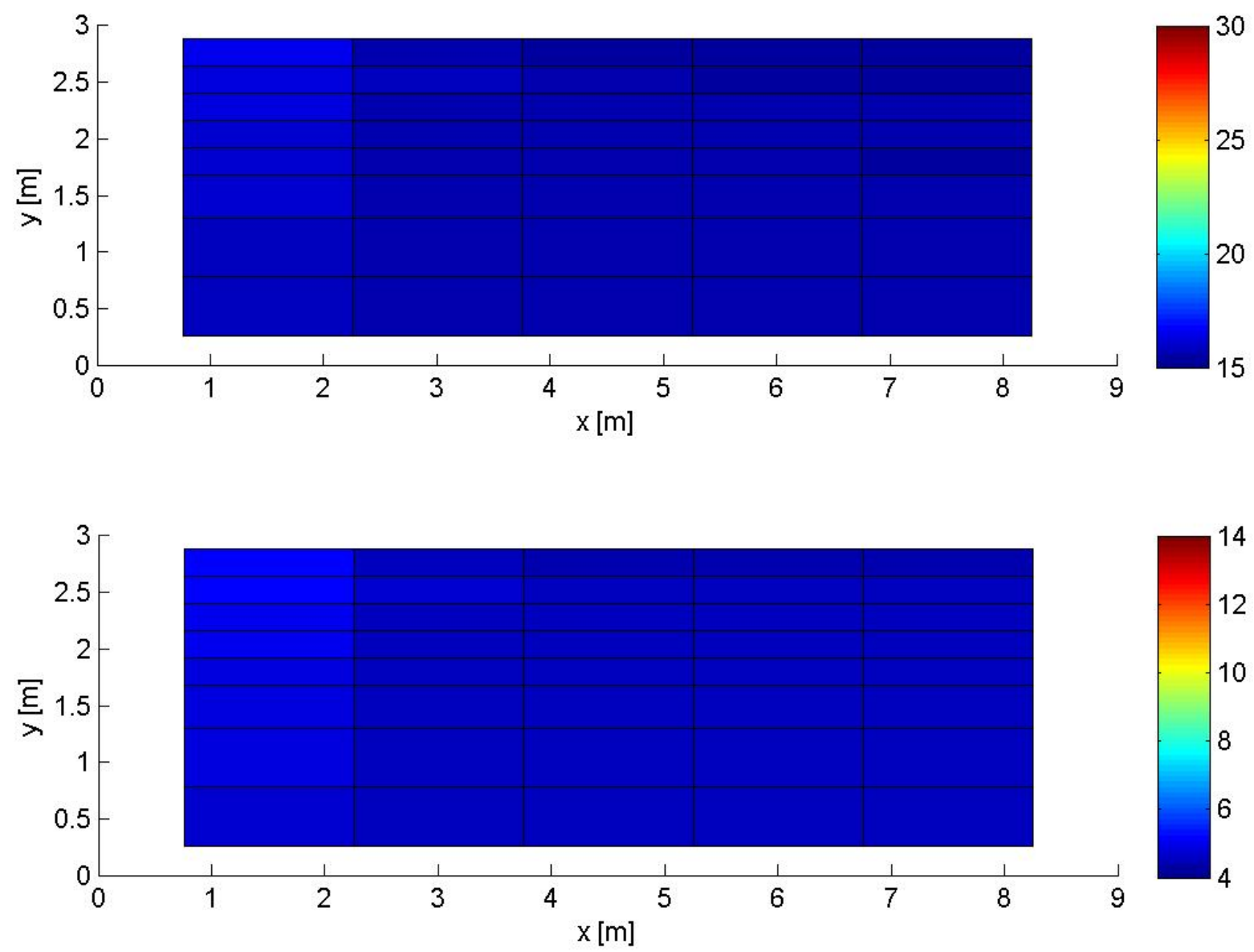

Figure 8: Temperature distribution $\left[{ }^{\circ} \mathrm{C}\right]$ (top) and vapour content distribution $\left[\mathrm{g} \mathrm{kg}^{-1}\right]$ (bottom) predicted by the sub-zonal model.
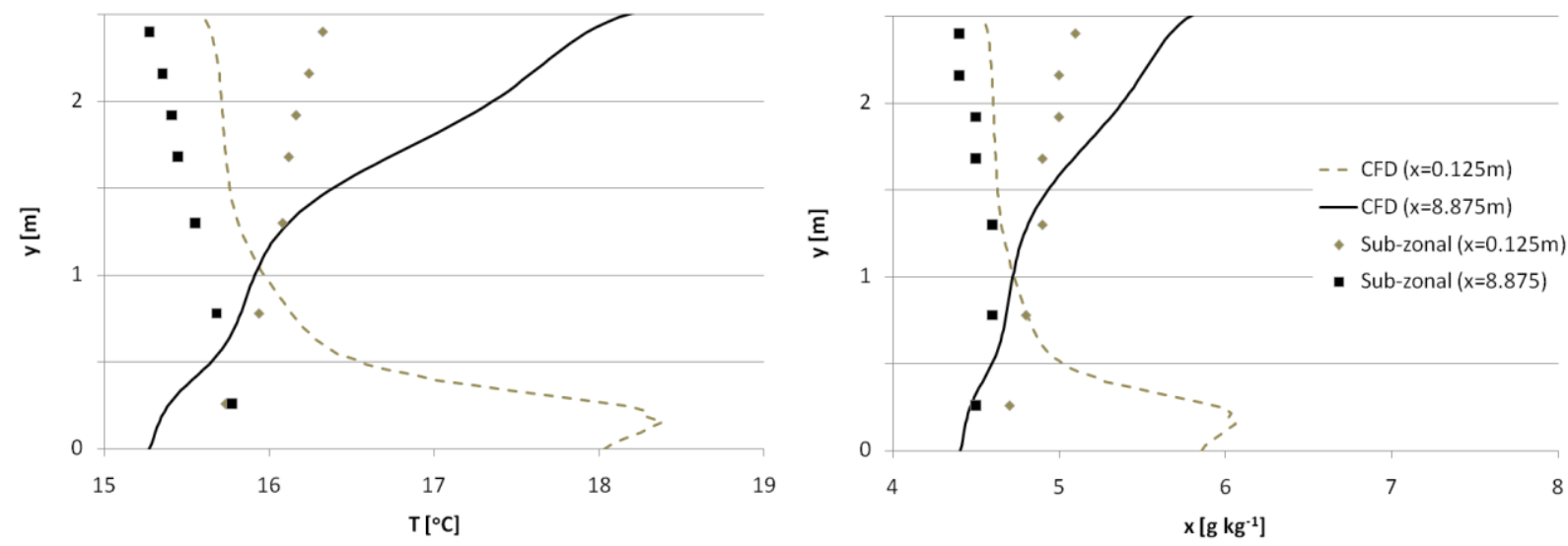

Figure 9: Temperature $\left[{ }^{\circ} \mathrm{C}\right]$ and vapour content $\left[\mathrm{g} \mathrm{kg}^{-1}\right]$ distribution at different locations in the room $(\mathrm{x}=0.125 \mathrm{~m}$ and $8.875 \mathrm{~m})$.

Other authors [11] [13] [30] [31] similarly indicated that the sub-zonal model is capable of giving a rough prediction of the forced convective airflow in the room provided an appropriate flow element model, describing the jet in the room, is implemented. In the research presented by Wurtz [13], the isothermal Annex 20 Benchmark case has been analyzed too. He concluded that sub-zonal models give a satisfactory 
Postprint: Steskens PWMH, Janssen H, Rode C, 2013. Evaluation of sub-zonal air flow models for the prediction of local interior boundary conditions - natural and forced convection cases, Indoor and Built Environment,22:395-409.

estimate of airflow patterns only with specific laws to model momentum added to the air by the jet. Subzonal models give a rough estimate of the structure of the recirculation in the room.

However, the study presented by Wurtz [13] did not focus on smaller local recirculation regions of the air, for example in a corner of the room. This study demonstrated that the sub-zonal airflow model is not capable of capturing such small recirculation regions, resulting in significant deviations of the local temperature and vapour content. In addition, the study [13] did not consider the prediction of the local temperature and vapour content near the building component specifically. While Wurtz [13] did not experience any problems with respect to the prediction of the local temperature in the room and observed that only small discrepancies between the sub-zonal model and experimental data were observed, larger deviations have been observed in the present study.

Besides the local temperature and vapour content, the convective surface transfer coefficients are important for the prediction of the heat and moisture flows between the room and the walls. The predicted convective surface heat and moisture transfer coefficients along the walls resulting from the sub-zonal models and the CFD have been compared. Table 4 presents an overview of the simulated surface transfer coefficient models and computational grids that have been used.

Figure 10 presents a comparison of the local convective surface heat and moisture transfer coefficients resulting from the different surface transfer coefficient models and with the values obtained from the CFD simulation. First of all, the figure shows that the relationships for average surface transfer coefficients obtained from Beausoleil-Morrison [5], i.e. model (a), are not applicable, since these result in an over-prediction by a factor 2 or more in the lower region of the left-hand wall and the upper region of the right-hand wall. Second, the figures show that the models based on the flat plate relationships obtained by Churchill [24], model (b), and Churchill and Ozoe [25], model (d), are not capable of predicting the convective surface heat transfer coefficient along both walls. The models give an under-prediction by a factor 10 or more. With respect to the flat plate based correlation reported by Rose [24], the predictions for the Western wall result in an over-prediction of the CFD results by a factor 2 and higher, while the correlation also does not give good results for the Eastern wall. The main reasons for the erroneous prediction of the local convective surface transfer coefficient by the surface transfer coefficient models based on the flat plate analogy may be found in the fact that these models are based on relationships that have been determined for isolated flat plates instead of real building components. The specific assumptions of the boundary layer theory for flat plates, for example regarding the boundary conditions, geometrical influences, entrance velocity and leading edges, and surface roughness, are not (entirely) valid in building enclosures, and may hence not be applicable for the airflow along walls that circumfere a room.

\begin{tabular}{|c|l|l|}
\hline MODEL & STC & Grid (x . y) \\
\hline (a) & $\begin{array}{l}\text { Beausoleil-Morrison \{\{505 Beausoleil- } \\
\text { Morrison, I. 2000; }\}\end{array}$ & $6 \times 9$ \\
\hline (b) & 1Flat plate (Churchill) [50] & $6 \times 9$ \\
\hline (c) & 2 Flat plate (Rose) [50] & $6 \times 9$ \\
\hline (d) & 3 Flat plate (Churchill and Ozoe) [60] & $6 \times 9$ \\
\hline (e) & $\begin{array}{l}\text { Local Beausoleil-Morrison \{\{505 Beausoleil- } \\
\text { Morrison, I. 2000; }\}\end{array}$ & $6 \times 9$ \\
\hline
\end{tabular}

Table 4: Applied surface transfer coefficient models and corresponding computational grids (forced convection)

Furthermore, the models require accurate prediction of the local Reynolds and Nusselt numbers near the wall. However, the sub-zonal model is not able to give an accurate prediction of the Reynolds and Nusselt numbers in the room. In the model, average Reynolds and Nusselt numbers were calculated for each face of the sub-zones parallel to the wall based on the average air mass flux through these faces. In principle, both the local Reynolds and Nusselt numbers are based on the local air mass fluxes. Since the sub-zonal model cannot give an accurate prediction of the local air mass fluxes, this means that an erroneous prediction of the air mass flux automatically results in an erroneous prediction of the Reynolds and Nusselt numbers and thus erroneous convective surface transfer coefficients. 
Postprint: Steskens PWMH, Janssen H, Rode C, 2013. Evaluation of sub-zonal air flow models for the prediction of local interior boundary conditions - natural and forced convection cases, Indoor and Built Environment,22:395-409.
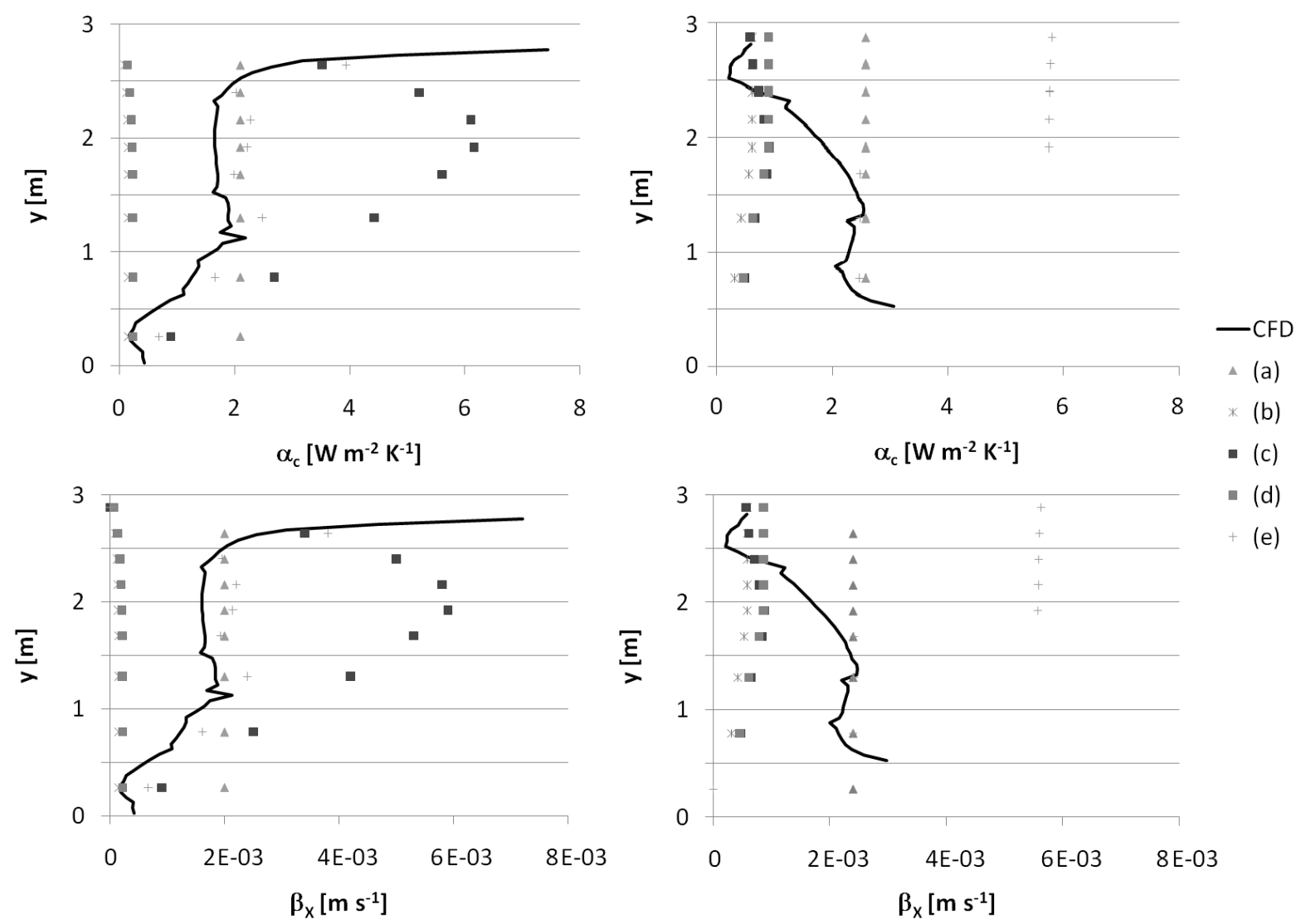

Figure 10: Convective surface heat transfer coefficient $\left(\alpha_{c}\left[\mathrm{~W} \mathrm{~m}{ }^{-2} \mathrm{~K}^{-1}\right]\right)$ and convective surface moisture transfer coefficient $\left(\beta_{X}\left[\mathrm{~m} \mathrm{~s}^{-1}\right]\right)$ for the left wall (left) and the right wall (right)

Figure 10 presents the calculated convective surface heat and moisture transfer coefficients from sub-zonal model (e). With respect to the left-hand wall, the figure shows that the model is able to predict the surface transfer coefficients in the same order of magnitude compared to CFD, while the relative deviation is approximately $30 \%$. Similarly, the model (e) is able to give a prediction of the surface transfer coefficients in the lower part of the right-hand wall with a relatively small deviation of $30 \%$, while a deviation of factor 3 and more is observed towards the ceiling. An explanation for these deviations might be found in the presence of a recirculation region in the upper right corner. As has been mentioned earlier, the sub-zonal model is not able to predict this recirculation of the air in the corner and this may therefore result in erroneous convective surface transfer coefficients. For additional information the reader is referred to [23].

\section{Conclusions}

In this paper, the capability and applicability of the sub-zonal airflow model to predict the local indoor environmental conditions as well as the local non-uniform surface transfer coefficients have been investigated. Two test cases for respectively natural and forced convection in a zone have been analyzed. The indoor environmental conditions in the zone predicted from the sub-zonal airflow models have been compared to experimental results and numerical results obtained from CFD. Moreover, the predicted surface transfer coefficients have been compared with numerical results from CFD. The sub-zonal models have been compared to CFD models based on two criteria: first, the ability of the model to predict the local temperature and relative humidity near the building component; second, the capability of the model to predict the local convective surface transfer coefficients.

The following has been concluded from this work: 
Postprint: Steskens PWMH, Janssen H, Rode C, 2013. Evaluation of sub-zonal air flow models for the prediction of local interior boundary conditions - natural and forced convection cases, Indoor and Built Environment,22:395-409.

- For natural convection, the sub-zonal model is able to give a prediction of the temperature and vapour content distribution in the room, with maximum deviations of around $3^{\circ} \mathrm{C}$ and up to $3 \mathrm{~g} / \mathrm{kg}$ compared to the temperatures and vapour contents predicted by CFD. With respect to the prediction of the local convective surface transfer coefficients the model based on the experimental correlations for natural convection in an enclosure developed by Turner et al. [27] gave predictions with a maximum relative deviation up to $10 \%$.

- $\quad$ Regarding forced convective airflow, the model showed to be applicable to give a rough prediction of the global temperature and vapour content distribution in the room with a maximum deviation of approximately $3^{\circ} \mathrm{C}$ and $1.5 \mathrm{~g} / \mathrm{kg}$. If local recirculation of the airflow is present, the relative deviation increases up to around $5^{\circ} \mathrm{C}$ for the local temperature and $2 \mathrm{~g} / \mathrm{kg}$ for the local vapour content. The surface transfer coefficient model gave relatively good results for regions where recirculation does not take place, while the relative deviation is approximately $30 \%$. The model cannot be applied in regions where local recirculation of the airflow takes place.

With respect to both case studies, it may be difficult to generalize the observations for natural and forced convection in a room. The present study and other researchers [37] [38] [43][46] showed that subzonal models are suitable to obtain a relatively rough prediction of the indoor environmental conditions compared to CFD. The present study also illustrated that for airflows dominated by natural or forced convection, sub-zonal models combined with an appropriate surface transfer coefficient model are applicable for the prediction of the local convective surface transfer coefficients in a room.

The study showed that sub-zonal models combined with an appropriate surface transfer coefficient model are able to give a prediction of the indoor environmental conditions in a room under natural or forced convective conditions. However, one important remark should be made. In the case studies, reference conditions, for example experimental data or numerical results from CFD, have been used for the development of a reliable sub-zonal airflow model. The availability of such reference conditions is a prerequisite for the development of a reliable sub-zonal model.

The main advantage of the sub-zonal model is a significant reduction in computational effort compared to CFD. The computation time of a sub-zonal airflow model with a surface transfer coefficient model implemented generally varies between a few seconds up to 20 seconds. The sub-zonal airflow model is solved on a relatively coarse grid, while only three equations, i.e. describing the conservation of mass, energy, and vapour, are solved per time step. The computational effort of the CFD simulations that have been carried out is relatively large. The computation time of a CFD simulation varies between several hours up to a few days. Furthermore, the stability of the sub-zonal model showed to be relatively large compared to CFD, resulting in only a few iterations for solving the airflow and the temperature and vapour content fields. The relatively short computation time and flexibility makes the application of the sub-zonal model attractive for the transient simulation of heat, air and moisture transport in buildings. 
Postprint: Steskens PWMH, Janssen H, Rode C, 2013. Evaluation of sub-zonal air flow models for the prediction of local interior boundary conditions - natural and forced convection cases, Indoor and Built Environment,22:395-409.

\section{References}

[1] Woloszyn M, Rode C: Tools for performance simulation of heat, air and moisture conditions of whole buildings: Building Simulation 2008; 1, 1: 5-24.

[2] Holm A: Ermittlung der Genauigkeit von instationären hygrothermischen Bauteilberechnungen mittels eines stochastischen Konzeptes. PhD Thesis, TU Munich, 2001.

[3] Janssen H, Blocken B, Carmeliet J: Conservative modelling of the moisture and heat transfer in building components under atmospheric excitation: Int. J. Heat Mass Transfer 2007; 50, 56: 1128-1140.

[4] Steskens PWMH, Janssen H, Rode C: Influence of the Convective Surface Transfer Coefficients on the Heat, Air, and Moisture (HAM): Building Performance 2009; 18, 3: 245256.

[5] Beausoleil-Morrison I: The adaptive coupling of heat and air flow modeling within dynamic whole-building simulation. PhD Thesis, University of Strathclyde, 2000.

[6] Mortensen LH: Hygrothermal Microclimate on Interior Surfaces of the Building Envelope. PhD Thesis, Technical University of Denmark, 2007.

[7] Roels S, Janssen H: A comparison of the Nordtest and Japanese test methods for the moisture buffering performance of building materials: Journal of Building Physics 2006; 30, 2:137-161.

[8] Abuku M, Janssen H, Roels S: Impact of wind-driven rain on historic brick wall buildings in a moderately cold and humid climate: Numerical analyses of mould growth risk, indoor climate and energy consumption: Energy and Buildings 2009; 41, 1: 101-110.

[9] Steeman HJ: Modelling Local Hygrothermal Interaction between Airflow and Porous Materials for Building Applications. PhD Thesis, Ghent University, 2008.

[10] Mendonça KC : Modelisation thermo-hydro-aeraulique des locaux climatises selon l'approche zonale. PhD Thesis, Université de La Rochelle, 2004.

[11] Teshome EJ, Haghighat F: Zonal Models for Indoor Air Flow - A Critical Review: International Journal of Ventilation 2004; 3, 2: 119

[12] Megri AC: Zonal Modeling for Simulating Indoor Environment of Buildings: Review, Recent Developments, and Applications: HVAC research 2007; 13, 6: 887.

[13] Wurtz E, Mora L, Inard C: An equation-based simulation environment to investigate fast building simulation: Building and Environment 2006; 41, 11: 1571-1583.

[14] Inard C, Bouia H, Dalicieux P: Prediction of air temperature distribution in buildings with a zonal model: Energy \& Buildings 1996; 24, 2: 125-132.

[15] Nielsen PV: Specification of a Two-Dimensional Test Case. University of Aalborg, Aalborg, 1990.

[16] Chen Q: Simulation of Simple Test Cases, Annex 20 Air flow patterns within buildings, Subtask 1: Room Air and Contaminant Transport, 1991.

[17] Allard F, Brau J, Inard C, Pallier JM: Thermal experiments of full-scale dwelling cells in artificial climatic conditions: Energy and Buildings 1987; 10, 1: 49-58.

[18] Nielsen PV, Restivo A, Whitelaw JH: Velocity Characteristics of ventilated rooms: Journal of Fluids Engineering Transactions of the ASME 1978; 100, 3: 291-298.

[19] Nicolai A, Grunewald J: CHAMPS-BES Program for Coupled Heat, Air, Moisture and Pollutant Simulations in Building Envelope Systems (User Manual). BEESL - Building Energy and Environmental Systems Laboratory, Department of Mechanical and Aerospace Engineering, Syracuse University, NY, Syracuse, NY, 2006.

[20] Siegel R, Howell JR: Thermal Radiation Heat Transfer. Hemisphere Publishing Corporation, Washington DC. 1992.

[21] Stewart J, Ren Z: COwZ-A sub-zonal indoor airflow, temperature and contaminant dispersion model: Building and Environment 2006; 41, 12: 1631-1648. 
Postprint: Steskens PWMH, Janssen H, Rode C, 2013. Evaluation of sub-zonal air flow models for the prediction of local interior boundary conditions - natural and forced convection cases, Indoor and Built Environment,22:395-409.

[22] Rajaratnam N: Turbulent Jets. Elsevier Scientific Publishing Company, Amsterdam - Oxford New York, 1976.

[23] Steskens PWMH: Modelling of the Hygrothermal Interactions between the Indoor Environment and the Building Envelope. Department of Civil Engineering (BYG), Technical University of Denmark (DTU), 2009.

[24] Schlichting H, Gersten K: Boundary layer theory. 8th edition, Springer Berlin Heidelberg, 2003.

[25] Cengel YA: Heat Transfer: A Practical Approach. McGraw-Hill, New York, 2003.

[26] Chilton TH, Colburn AP: Mass transfer (absorption) coefficients: Industrial and Engineering Chemistry $1934 ; 26: 1183-1187$.

[27] Turner BL, Flake LD: The experimental measurement of natural convection heat transfer in rectangular enclosures: ASME Transactions Journal of Heat Transfer 1980; 102: 236-241.

[28] Bohn MS, Kirkpatrik AT, Olson DA: Experimental study of three-dimensional natural convection and high Rayleigh numbers: ASME Transactions Journal of Heat Transfer 1984; 106: 339-384.

[29] Khalifa AN: Natural convective heat transfer coefficient - a review : II. Surfaces in two- and three-dimensional enclosures: Energy Conversion and Management 2001; 42, 4: 505-517.

[30] Axley JW: Surface drag flow relations for zonal modelling: Building and Environment 2001; 36, 7: 843-850.

[31] Mora L, Gadgil J, Wurtz E: Comparing zonal and CFD model predictions of isothermal indoor airflows to experimental data: Indoor Air 2003; 13: 77-85. 